\title{
A better way in: improving patient outcomes in endovascular aneurysm repair by using percutaneous access
}

\begin{abstract}
EVAR has revolutionized the care of patients with aortic abdominal aneurysms and efforts to evolve the technique continue, with aim of improving patient experience and outcomes. We aimed to collect objective data related to using percutaneous access in EVAR operations in our unit in Aberdeen Royal Infirmary, with particular focus on post-operative complications. We found that nearly all patients (11 out of 12 ) who underwent percutaneous EVAR or FEVAR in Aberdeen Royal Infirmary since the introduction of the technique did so without experiencing any post-operative wound complications. This case series reflects the success and benefits of the use of percutaneous EVAR in our unit and also contributes to current evidence base for the use of the technique in selected patient groups.
\end{abstract}

Keywords: abdominal aneurysms, endovascular aneurysm, computer tomography, vascular surgery, preclose technique
Volume 6 Issue 3- 2018

\section{Gabija Lazaraviciute, Sharon Yen Ming Chan, Kristy Kehoe, Kirsty Hudson, Paul Bachoo, Alasdair Wilson, Bryce Renwick}

Department of Vascular Surgery, University of Aberdeen, UK

Correspondence: : Gabija Lazaraviciute, Department of Vascular Surgery, University of Aberdeen, Academic Foundation Year 2 Doctor, UK, Email gabija.lazaraviciute@nhs.net

Received: January 18, 2018 | Published: June 18, 2018

\section{Introduction}

Endovascular aortic aneurysm repair (EVAR) has revolutionized the care of patients with aortic abdominal aneurysms. Whilst EVAR 1 trial showed an early survival benefit of EVAR, as compared to open abdominal aortic aneurysm repair, efforts still continue to minimize the surgical stress on patients and decrease the perioperative morbidity. ${ }^{1}$ Percutaneous endovascular aneurysm repair (P-EVAR) offers minimally invasive access, with potential for decreased postoperative pain and quicker post-operative recovery. In addition to this, several studies have shown decreased wound complication rates with P-EVAR and as such, strengthen the rationale for use of P-EVAR in suitable patient groups. ${ }^{2-4}$ Suitable patient groups are often identified after a multidisciplinary team discussion, however, in general terms, P-EVAR can be the appropriate choice of technique in the low-risk patients, who have suitable access vessels with no significant stenosis at the back wall and with healthy anterior walls.

With evidence in favor of percutaneous access EVAR growing, the technique was introduced in Aberdeen Royal Infirmary in early 2017. This reflects a change in practice and an evaluation of the service has therefore been initiated. We sought to detail all percutaneous endovascular aneurysm repairs (including fenestrated endovascular aneurysm repairs (FEVAR)) performed in Aberdeen Royal Infirmary, with particular focus on post-operative complications. The collated data then allowed us to assess whether the introduction of P-EVAR has been of benefit to our patients. This case series will also contribute to current evidence base for the use of P-EVAR in selected patient groups.

\section{Methods}

Patients suitable for percutaneous EVAR or FEVAR access were identified preoperatively using computer tomography angiograms and discussion at the multidisciplinary vascular surgery and interventional radiology meeting. Generally, femoral arteries were deemed suitable if they had less than $30 \%$ stenosis at the posterior wall and had healthy anterior walls.

We aimed to identify all patients receiving percutaneous EVAR and FEVAR since the introduction of such practice in Aberdeen Royal Infirmary in early 2017 (meaning that all patients who received percutaneous FEVAR or EVAR in our unit between January 2017 and December 2017 were identified). Three different surgeons performed the cases, all with similar training in percutaneous endovascular aneurysm repair. All femoral arteries were punctured under ultrasound guidance and standard $\mathrm{j}$-wires were advanced under fluoroscopy. The tracts were then dilated with 8 French dilators prior to deployment of the proGlide devices (Abbott Medical). After the endovascular hardware had been withdrawn, the arteriotomies were closed with the preclose technique and manual pressure was then applied. The following details were recorded for each patient: procedure type, sheath size, number of proGlide devices used. We also sought out information about any access site bleeding, femoral pseudo aneurysm, conversion to operative repair, femoral artery thrombosis/ embolization and groin infection.

\section{Results}

12 patients were identified in the investigated period: 2 of these underwent percutaneous FEVAR and 10 underwent percutaneous EVAR. (Table 1) All patients had percutaneous access performed bilaterally, amounting to a total of 24 arteries being closed with ProGlide devices via the preclose technique. In 2 of the procedures performed, ProGlide failed to deploy properly and therefore additional ProGlide had to be used (shown as $2+1+2$ in the table when one additional ProGlide was needed and $2+2+2$ when two additional proGlide devices were needed).

None of the patients who had percutaneous access suffered any haematomas, false aneurysms, arterial occlusions (thrombosis or embolization) or groin infections. One patient (patient number 11 in 
the table below) suffered from bleeding from the left percutaneous access site 36hours post-procedure, however this settled with prolonged manual pressure. No interventional procedures were needed to repair this Discussion. Nearly all patients who underwent percutaneous EVAR or FEVAR in Aberdeen Royal Infirmary since the introduction of the technique earlier this year did so without experiencing any post-operative wound complications. One patient experienced bleeding at the left access site, which settled with manual pressure (the right access site had no complications attached to it). The above results are in keeping with some previous studies on this subject, which have also shown decreased wound complication rates with P-EVAR, as compared to the cut down technique. ${ }^{2-4}$

Use of percutaneous access for our EVAR and FEVAR patients has proven a safe technique in correctly selected patient groups with minimal risk of complications so far. In addition to reduced complication risk, percutaneous access in EVAR cases also allows for easier re-do operations in the future if such are needed, for example, for an extension of the graft.

However, despite our positive findings, more research is needed to provide clinicians with high-quality evidence for their practice. A recent systematic review acknowledged the limited number of studies currently available and further analysis of the technique will be beneficial. ${ }^{5}$ Continued use of percutaneous access in EVAR and FEVAR will allow us to further re-examine evidence in the future and continue to seek ways to improve the quality of the service we deliver for our patients.

\begin{tabular}{|c|c|c|c|c|c|c|c|c|c|}
\hline Patient & $\begin{array}{l}\text { Procedure } \\
\text { performed }\end{array}$ & Access & $\begin{array}{l}\text { Number } \\
\text { of pro } \\
\text { glide } \\
\text { devices }\end{array}$ & Bleeding & Haematoma & $\begin{array}{l}\text { False } \\
\text { aneurysm }\end{array}$ & $\begin{array}{l}\text { Arterial } \\
\text { thrombosis or } \\
\text { embolisation }\end{array}$ & $\begin{array}{l}\text { Groin } \\
\text { infection }\end{array}$ & $\begin{array}{l}\text { Conversion } \\
\text { to open }\end{array}$ \\
\hline I & EVAR & $\begin{array}{l}\text { Right } \\
18 \mathrm{Fr} / \text { Left } \\
12 \mathrm{Fr}\end{array}$ & $2+2$ & No & No & No & No & No & No \\
\hline 2 & $\begin{array}{l}\text { EVAR(aorticectasia } \\
\text { and } \\
\text { rightiliacaneurysm) }\end{array}$ & $\begin{array}{l}\text { Right } \\
18 \mathrm{Fr} / \text { Left } \\
12 \mathrm{Fr}\end{array}$ & $2+2+2$ & No & No & No & No & No & No \\
\hline 3 & EVAR & $\begin{array}{l}\text { Right } \\
18 \mathrm{Fr} / \text { Left } \\
12 \mathrm{Fr}\end{array}$ & $2+1+2$ & No & No & No & No & No & No \\
\hline 4 & 4-fen FEVAR & $\begin{array}{l}\text { Right } \\
24 \mathrm{Fr} / \text { Left } \\
20 \mathrm{Fr}\end{array}$ & $3+3$ & No & No & No & No & No & No \\
\hline 5 & 3-fen FEVAR & $\begin{array}{l}\text { Right } \\
24 \mathrm{Fr} / \text { Left } \\
20 \mathrm{Fr}\end{array}$ & $3+3$ & No & No & No & No & No & No \\
\hline 6 & EVAR & $\begin{array}{l}\text { Right } \\
12 \mathrm{Fr} / \text { Left } \\
18 \mathrm{Fr}\end{array}$ & $2+2$ & No & No & No & No & No & No \\
\hline 7 & EVAR & $\begin{array}{l}\text { Right } \\
18 \mathrm{Fr} / \text { Left } \\
16 \mathrm{Fr}\end{array}$ & $2+2$ & No & No & No & No & No & No \\
\hline 8 & EVAR & $\begin{array}{l}\text { Right } \\
16 \mathrm{Fr} / \text { Left } \\
12 \mathrm{Fr}\end{array}$ & $2+2$ & No & No & No & No & No & No \\
\hline 9 & EVAR & $\begin{array}{l}\text { Right } \\
16 \mathrm{Fr} / \text { Left } \\
12 \mathrm{Fr}\end{array}$ & $2+2$ & No & No & No & No & No & No \\
\hline 10 & EVAR & $\begin{array}{l}\text { Right } \\
18 \mathrm{Fr} / \text { Left } \\
16 \mathrm{Fr}\end{array}$ & $2+2$ & No & No & No & No & No & No \\
\hline II & EVAR & $\begin{array}{l}\text { Right } \\
18 \mathrm{Fr} / \text { Left } \\
16 \mathrm{Fr}\end{array}$ & $2+2$ & Yes & No & No & No & No & No \\
\hline 12 & EVAR & $\begin{array}{l}\text { Right } \\
18 \mathrm{Fr} / \text { Left } \\
16 \mathrm{Fr}\end{array}$ & $2+2$ & No & No & No & No & No & No \\
\hline
\end{tabular}

\section{Conclusion}

Percutaneous EVAR and FEVAR has been successfully introduced in Aberdeen Royal Infirmary and has shown excellent results so far with regards to bleeding, haematoma, false aneurysm, arterial occlusion and groin infection risk. Continued use of the technique will allow for more robust and extensive assessment of the outcomes, however this case series acts as a good pilot study reflecting the successful work done by our clinicians so far.

\section{Acknowledgements}

None.

\section{Conflict of interest}

Author declares that there is no conflict of interest. 


\section{References}

1. EVAR Trial Participants. Endovascular aneurysm repair versus open repair in patients with abdominal aortic aneurysm (EVAR trial 1): randomised controlled trial. Lancet. 2005;365(9478):2179-2186.

2. McDonnell CO, Forlee MV, Dowdall JF, et al. Percutaneous endovascular abdominal aortic aneurysm repair leads to a reduction in wound complications. Ir J Med Sci. 2008;177(1):49-52.

3. Jean Baptiste E, Hassen Khodja R, Haudebourg P, et al. Percutaneous Closure Devices for Endovascular Repair of Infrarenal Abdominal
Aortic Aneurysms: A Prospective, Non-randomized Comparative Study. European Journal of Vascular and Endovascular Surgery. 2008;35(4);422-428.

4. Renwick B, Montgomery S, Hamid H, et al. Challenges and Solutions in Day Case EVAR. J Anesth Crit Care Open Access. 2016;6(4):1-2.

5. Gimzewska M, Jackson AI, Yeoh SE, et al. Totally percutaneous versus surgical cut-down femoral artery access for elective bifurcated abdominal endovascular aneurysm repair. Cochrane Database Syst Rev. 2017;21(2):CD010185. 